\title{
A Study of Gifted Education for Cultivating 'Top-Notch, Innovative Talent' in a Western Chinese High School
}

\author{
Liu Peng, Hu Shaoming \\ Education College, Baoji University of Arts and Sciences, Baoji, China \\ Email address: \\ 474178711@qq.com (Liu Peng),694679574@qq.com (Hu Shaoming)
}

\section{To cite this article:}

Liu Peng, Hu Shaoming. A Study of Gifted Education for Cultivating 'Top-Notch, Innovative Talent' in a Western Chinese High School. Science Journal of Education. Vol. 6, No. 3, 2018, pp. 94-102. doi: 10.11648/j.sjedu.20180603.14

Received: April 20, 2018; Accepted: June 6, 2018; Published: June 20, 2018

\begin{abstract}
Top-notch innovative talent, it is to point to in various areas especially in science, technology and management, with innovative spirit and ability, to make a significant contribution to the development of national outstanding talents." As China focuses on the cultivation of a new generation of top-notch innovative talent in its senior high schools, many difficulties have begun to emerge, which are new and perplexing to school leaders and teachers. This project followed top-notch, innovative, and talent cultivating classes at G Senior High School in western China from the perspective of educational management, in carrying out the mode and measures in the process of its, problems and reasons, and puts forward the countermeasures to solve the problems. Our study analyzed G School and specifically highlighted its programs for frequent and regular teacher training, diversification of student selection, expansion of extracurricular activities, and specialization of art education. The fourth part analyzes the problems and causes of the school's mode and measures through the production and distribution of questionnaire. The problems are mainly focused on different social recognition, Hysteresis of the cohesion of teachers' quality, low quality of students, science orientation curriculum setting, and low graduation output rates. In the fifth part, the author makes suggestions to improve innovative talents teaching and management in senior high schools through cooperation with universities, as well as increasing media visibility and public awareness, professional training and qualification assessment, scientific student selection and expansion enrollment, balancing the courses and strengthening liberal education, and multiple outputs.
\end{abstract}

Keywords: Innovative Talent, Senior High School, Mode, Measures

\section{Introduction}

"Follow the rules of education development and the law of talents' growth, deepen education and teaching innovation, bring forth new ideas about education and teaching methods, explore a variety of ways to form a situation of emerging all kinds of talented people and top-notch innovative talents constantly." [1]

Traditionally, the cultivation of innovative talents in China has centered around universities, though in recent years, it has also turned to public senior high schools. Senior high school acts as a key link between basic and higher education as a link in our country and, by cultivating top-notch innovative talents in high school, it can lay a solid foundation for further development in higher education. Therefore, we should follow the teaching rules of senior high school education, attach more importance to the development of individual students' abilities and spirit, constantly explore the right means of education, and form a scientific mode of education to further the rejuvenation of China through the development of the plentiful human resource available.

This paper takes G Senior High School in western China as an example, based on the author's investigation of the advantages and disadvantages of the top-notch innovative talents cultivating process, and analyzed other similar experiments at home and abroad to draw conclusions for how to optimize education mode and measures and promote the future career of innovative talents in regular senior high schools in not only western China, but all across our country.

\section{Definition of Concepts}

\subsection{The Concept of "Top-Notch Innovative Talents"}

Educational psychologist Joseph Renzulli deemed they didn't consider non-intelligence elements when giving the 
definition to Gifted children. So he put forward complementary "three-ring model", and pointed out that gifted and talented children have three factors: above average intelligence, the high level of creativity and strong learning motivation. It is necessary to provide special education to these children and young people.

In the United States, children who exhibit genius in intelligence, creativity, leadership, visual arts, or academic performance ability are designated as "gifted and talented" or "gifted children" along standards set by the Department of Education.

In South Korea, the Promotion Act for the Gifted and Talented Education was passed in 2000 and first recognized "talent" as teenagers with special gifts and talents that the nation should supply with special education according to their needs.

The earliest mention of a "gifted child" in China comes from a special class for gifted children hosted by the Beijing-based University of Science and Technology in China in 1978. The term "top-notch innovative talents" was first introduced by Jiang Zemin during an address at the Sixteenth National Congress of the Communist Party and later expounded upon by Chen $\mathrm{Xi}$ in his paper "Cultivating Top-Notch Innovative Talents in Accordance with the Party's Education Policy." [2] Subsequently, with the continuous improvement of knowledge and practice, the cultivation of a large number of innovative talents has become an important part of China's Power Nation Strategy.

\subsection{Cultivating Modes Abroad and in China}

The American education system has among the most mature models for cultivating innovative talents, with William Torrey Harris formulating one of the earliest developed systematic learning solutions, beginning in 1868. The "acceleration model" is used most widely among gifted students, allowing them to skip to higher grades when necessary.

However, there are also several other models for cultivating talented students, including Acceleration and Enrichment Mode, Pursue Advanced Study on Three Factors Mode, Identify and Develop Talents Mode, Mick's Intellectual Structure Model, Bloom's Taxonomy, and the Osborn-Parnes Creative Problem Solving Process.

In addition, Singapore's "Genius Education" adopts the government-led "Enrichment System" mode, and South Korea's "Talents Education" adopts the "Trinity" mode.

The typical cultivating mode in Chinese regular senior high schools is the "Senior secondary school + Top Universities" mode, which partners senior high schools and universities. [3] At present, these kind of academic outposts are mostly featured in top universities in top-tier cities. Examples include Beijing's "Plan Flying" (which concentrates on students' academic foundations and prominent interests, while highlighting practice and teamwork), Shaanxi province's "Explosion Plan" (which invites university experts to open laboratory teaching, using the "Trinity" method), and Shanghai's "Regular senior high school student innovative literacy cultivation experiment project" (a pilot program run through the central government, in which 20 well-known high schools in 7 provinces are partnered with Tongji University for joint cultivation, credit authentication, and credits docking). [4]

\subsection{Cultivating Measures Abroad and in China}

The United States set up "American Honors" Courses nationwide for those senior high school students who have extra studying capacity. They can choose from 34 AP courses (Advanced Placement Courses) in 22 categories and, by successfully passing an examination at the end of course, receive transfer credits after entering college. [5] Howard Gardner, the current Hobbsian Professor of Cognition and Education at Harvard University, proposed the theory of multiple intelligences in 1983, which has since been vigorously promoted in educational reform in the U.S. Gardner's theory posits that human intelligence can be categorized as not just one general ability, but rather divided into eight different types: language, logic and mathematics, space, sports, music, interpersonal communication, introspection, and natural observation. The curriculum of AP courses in the United States, formulated along the lines of the theory of multiple intelligence, plays a protective role in promoting the cultivating process of education. [6]

Japan instituted the "Super Science Senior High School Program" in 2002, focusing on mathematics, science, and technology in high school education as part of its 2001 Science and Technology Basic Plan to bolster its scientific and technological output - most notably with the goal of producing 50 Nobel laureates in the next 30 years.

The methods of cultivating innovative talent in Chinese senior high schools consist mainly of the tutorial system, the optional class system, and the compulsory elective courses system. The tutorial system is best represented by the Nanjing Chong Wen class: University scholars and academic experts come to school campuses, to not only guide the cultivation of top-notch innovative talent, but also expose students to college classroom teaching methods to prepare for higher education. [7]

The optional class system ensures students' autonomy in selecting courses in senior high school, in order to encourage them in their interests and hobbies. With the reform of the college entrance examination system in recent years, compulsory elective courses have increasingly been integrated into school curriculums to pay more attention to the development of students' individuality. [8] In order to fulfill the requirements of the syllabus, the school sets the elective courses according to the objectives and plans for independent cultivation.

\section{Taking G Senior High School in Western China as an Example}

\subsection{Background Introduction}

For an example of the third form of innovative talent 
cultivation in China, we can turn to G Senior High School, a full-time public senior high school in western China, as an example. In addition its standard curriculum, it has been developing a range of top-notch innovative talent cultivating classes since 2011. Their process has been guided by the concept of "liberal education," by ensuring students' exposure to the arts, humanities, and civic responsibilities.

There has also been a great emphasis on internationalism, the advocation for greater understanding between peoples and nations, as can be seen on its mottoes of "education should be geared to the needs of modernization, the world, and the future" and "multiform opening, harmonious development, education through practice and art."

The author developed and conducted a survey of G Senior High's top-notch innovative talents, using separate questionnaires for students and teachers. The design of questionnaires followed three steps: to understand the variable of study, to redact the questionnaires and issue the questionnaires.

\subsection{Characteristics of Its "Top-Notch Innovative Talent Class"}

\subsubsection{Regular and Frequent Teacher Training}

As the most important core force in the construction of top-notch innovative talents cultivating system, excellent faculty strength is the "speed catalyst" and "quality guarantee" in the process education.

It is of great importance to build a team of teachers with an excellent professional knowledge, advanced teaching concepts, innovative practice and excellence. In this aspect, firstly, G Senior High focused a strategy of "Recruit In" and "Send Out." The first measure refers to a focused recruitment of newly graduated teachers, with an emphasis on those trained in new techniques and with a passion for scientific innovation, to meet the increasing school needs.

The second measure, on the hand, refers to "sending out" current teaching faculty to both short- and long-term training to teachers who have years of teaching experience in higher education institutions. Short-term training projects were often held in famous middle schools in Beijing, Shanghai city, Jiangsu, Guangdong provinces and Xi 'an. Through this way, teachers study and discuss together, and it has create a batch of excellent teachers with unique styles for $\mathrm{G}$ school. At present, there are 16 teachers got master's degree and 2got Phd degree.

In addition to this strategy of investing in their faculty, $G$ Senior High would habitually invite professors and experts from nearby universities for not only guiding curriculum and management of TNITC, but also systematic and professional teacher training.

\subsubsection{Nuanced Student Selection}

The selection of motivated students is one of the most basic guarantees for the high quality cultivation of innovative talents. G Senior High's selection methods can be said to follow three basic principles: fairness in not allowing cheating or personal connections to benefit some applicants, adherence to judgment criteria that can be objectively quantified and evaluated, and flexibility in accepting borderline cases that display "special talents" the school may help cultivate.

The selection process itself consists of a recommendation by a parent, teacher, or the student themselves; review of academic performance; written test; oral interview; and demonstration of any noted special abilities or artistic specialties. Students themselves participate in an integrity test, selection result recorded, a comprehensive liberal test, and a personal interview.

The first of these student-based tests is of the student's integrity, with the student being left to take a written exam in a room with no teacher supervision, while hidden cameras monitor them for any sign of cheating (which results in an automatic fail).

Second, school take the selection as the first step getting to know the students, so the final result including analysis of data will be kept in the student file.

The third test is a comprehensive exam of both liberal arts and science questions, taken over 2-3 hours and meant to test the limits of a student's knowledge and reading ability. Finally, the end interview with a teacher is meant to act as both an extension and supplement for the above tests, to generate a more complete picture of the applicant. The interviewing students grade against personal appearance, civility and politeness, language ability, response speed, reading ability, and spoken English.

Since it was first employed in September 2011, the enrollment plan has gradually improved with every year. Through years of accumulated experience, G School today has both a unique recruitment system and student application process.

\subsubsection{Expansion of Extracurricular Activities}

In comparison to the traditional classroom, extracurricular activities can feature the information from traditional teaching methods, while getting rid of the spacial limitations of a closed and desensitized environment. This teaching form has always attracted students' interest, effectively combining theoretical knowledge with first-hand experience. These can be especially important for senior high school students to learn and grow, who are at a critical stage for learning and growing physically and mentally.

Students at G Senior High do one of many extracurricular activities every month, such as visiting museums or historical sites, attending orchestral and drama performances, also attending some community service, scuh as volunteer with local orphans and senior citizens, and tour the nearby water plant to understand its construction and function. They have even twice visited a winter camp in Canada to experience its very different culture. These activities have greatly enriched the worldview of these students, providing a outlet to apply their accumulated knowledge and provide a comprehensive platform for cultivating top-notch innovative talents.

\subsubsection{Specialized Art Education}

Good art education can greatly contribute to the cultivation of human cognition and creative ability, by fostering the nonlinear thinking and unorthodox approaches necessary in 
invention and creation. Many of the world's most famous scientists, for example, also have artistic pursuits or hobbies on the side. So it can be said that cultivating top-notch innovative talents and promoting art education are complementary.

G Senior High has worked hard to instill comprehensive talents for the development of science, humanities, and art in its students. Art education in particular has been show to benefit performance in other subjects, as well as adjust the fast pace and high frequency knowledge input for students. In addition to accepting art as one of the potential areas to show "special talent" in the admissions process, G Senior High has organized art clubs and offered classes for choir, violin, guzheng, dance, calligraphy, as well as forming a school band and orchestra. At the end of every school year, there is a study report and art performance, all planned and performed by the students of TNITC.

\section{Educational Barriers}

\subsection{Social Unawareness}

Society is made up of many different people, working in specialized positions in many different industries. Thus, many are not engaged in the work of professional educators, so they are unfamiliar with the idea of "cultivating top-notch innovative talent" and the logic behind G Senior High's educational management. They may even mischaracterize "top-notch innovative talents cultivating" as "educational injustice" or simply "heavy duty class" that shouldn't be allowed in our country. These misconceptions can create barriers and even generate negative stigmas.

Table 1. The degree of understanding of the concept of TNITC.

\begin{tabular}{lllll}
\hline Job & $\begin{array}{l}\text { Very } \\
\text { clear }\end{array}$ & $\begin{array}{l}\text { Know } \\
\text { some }\end{array}$ & Heard & $\begin{array}{l}\text { Never } \\
\text { heard }\end{array}$ \\
\hline Civil servant & $10 \%$ & $25 \%$ & $15 \%$ & $0 \%$ \\
Teacher & $20 \%$ & $6 \%$ & $3 \%$ & $0 \%$ \\
Businessman & $0 \%$ & $3 \%$ & $50 \%$ & $20 \%$ \\
\hline
\end{tabular}

\subsection{Stratified School Faculties}

Because G Senior High has featured regular education for much longer than its relatively recent "top-notch innovative talents" program, the majority of its teachers only have long experience with traditional teaching methods mostly focused on exams. They lack cutting-edge knowledge about teaching concepts such as "top-notch" and "innovation." And, unlike their seniors, the newer batch of young teachers bring new things to the table: high academic qualifications, strong professionalism, renewed passion for innovation, and more sensitive to the objective realities of the local environment. But these young teachers are for now a minority, with their numbers unable to justify the resources they require. The result can be school faculties that are stratified between teachers of different age and philosophy, bringing tensions and uneven overall quality of teaching.
Table 2. Teachers' teaching years and qualities.

\begin{tabular}{lllll}
\hline Years & \multirow{2}{*}{ Creativity } & $\begin{array}{l}\text { Professional } \\
\text { Knowledge }\end{array}$ & $\begin{array}{l}\text { Scientific } \\
\text { Management }\end{array}$ & $\begin{array}{l}\text { New } \\
\text { Thinking }\end{array}$ \\
\hline $1-2$ & $65 \%$ & $75 \%$ & $40 \%$ & $70 \%$ \\
$3-5$ & $55 \%$ & $70 \%$ & $58 \%$ & $60 \%$ \\
$5-8$ & $50 \%$ & $64 \%$ & $60 \%$ & $50 \%$ \\
$>8$ & $45 \%$ & $55 \%$ & $55 \%$ & $45 \%$ \\
\hline
\end{tabular}

\subsection{Disadvantaged Students}

G Middle School provides many of the students for $G$ Senior High, with both located in a third-tier city in the western region of China, a part of the country that has long lagged behind other regions in both economic development and educational achievement. Students there face a much more uphill battle than their more eastern counterparts in accessing their right to education, mostly from lack of money and the great distances between home and schools. In the end, only a few top creative talents are found among the students and can participate in the G Senior High's special programs.

This top-notch innovative talent cultivation environment represents a huge gap between the $\mathrm{G}$ schools and the more developed areas in China. Students who are unprepared for the rigor or methods of top-notch innovative talent cultivation will not only struggle academically, but threaten the efficiency of teachers in their lessons as well.

Table 3. Analysis of students' source and learning abilities.

\begin{tabular}{lllll}
\hline Student Background & Grades & $\begin{array}{l}\text { Art } \\
\text { Talent }\end{array}$ & $\begin{array}{l}\text { Reading } \\
\text { Habits }\end{array}$ & $\begin{array}{l}\text { Practical } \\
\text { Ability }\end{array}$ \\
\hline City, key school & High & High & High & High \\
Suburb, key school & Middle & High & Middle & High \\
Suburb, normal school & Middle & Middle & High & High \\
Rural school & Low & Low & Middle & Middle \\
\hline
\end{tabular}

\subsection{Science Orientation Curriculum Setting}

At the time of writing this article, the western region $G$ middle school has not entered the new college entrance examination reform. At present, although the school curriculum has made significant achievements, under the concept of liberal education, $G$ school tries to balance the liberal arts education simultaneously, but the unbalanced situation of " 'top-itch' gets science students top, 'innovative' innovates science". And most of the experts invited into school are natural science professors and scholars. Of course, this result is not caused by the school, it is led by the current national high school education direction and policy.

Table 4. Comparison of curriculum Settings between Art \& Science classes.

\begin{tabular}{lllll}
\hline class & $\begin{array}{l}\text { Syllabus } \\
\text { class }\end{array}$ & $\begin{array}{l}\text { Practice } \\
\text { after class }\end{array}$ & experiment & $\begin{array}{l}\text { Science } \\
\text { report }\end{array}$ \\
\hline Art class & $100 \%$ & $50 \%$ & $20 \%$ & $40 \%$ \\
Science class & $100 \%$ & $50 \%$ & $70 \%$ & $60 \%$ \\
\hline
\end{tabular}

\subsection{Graduation Output Channel Is Single}

Talent output is the key and the important embodiment of talent training quality. Students from top-notch innovative 
talents class accepted three years of special education, their thoughts have possessed characteristics with internationalization, antecedents and innovation. But insufficiently, The basic output of top-notch innovative talents class in $\mathrm{G}$ senior high school eventually is only the national college entrance examination. The output path of talent graduation is too monotonous, which can not reflect the significance of cultivating innovative talents in this high school. And it is easy to create a false impression of high quality high school ordinary graduates. This will form a social cognitive bias, and it is possible to enter the vicious circle of difficult recruitment in the next step.

Table 5. Statistics of graduate output methods in recent years.

\begin{tabular}{lllll}
\hline $\begin{array}{l}\text { Graduate } \\
\text { Year }\end{array}$ & CEE & $\begin{array}{l}\text { Independent } \\
\text { Recruitment }\end{array}$ & Art Exam & $\begin{array}{l}\text { Study } \\
\text { Abroad }\end{array}$ \\
\hline 2017 & $100 \%$ & $0 \%$ & $0 \%$ & $0 \%$ \\
2016 & $98 \%$ & $1 \%$ & $1 \%$ & $0 \%$ \\
2015 & $96 \%$ & $0.00 \%$ & $2.00 \%$ & $4.00 \%$ \\
2014 & $93.00 \%$ & $1.00 \%$ & $1.00 \%$ & $5.00 \%$ \\
\hline
\end{tabular}

\section{Strategies for Improving Mode and Measures}

\subsection{Strengthen Media Publicity and Enhance Society Recognition}

The school administration should advertise and popularize the concept of "top-notch innovative talents cultivating" to the public in this city through media and other means. According to people's common understanding of education fairness, usually fair means "equal treatment", some think top innovative talents cultivation is for excellent aptitude students with specialized cultivating, so that means "to discriminate", so it is easy to regard top-notch innovative talent cultivating as education unfair phenomenon. [9] In fact, education fairness is consistent with the cultivation of top-notch innovation. From the extension and representation of meaning of education fairness, the fairness of education also experienced a process from similar fairness to the different fairness. The core of the righteous is rationality between the change of the fairness.

\subsection{Professional Training and Qualification Assessment}

First of all, to the top-notch innovative talent classes in regular high schools in China, it is necessary to keep the original professional training for teachers, additionally schools should open lectures, train teachers in good Universities and enroll more excellent experts. Secondly, suggest government and education administration bring in "top-notch innovative registered teachers" system. Government and schools should encourage teachers to take professional training and take the exams to be registered. Hope our country could issue the policy scheme as soon as possible, for our country could cultivate a batch of high school top creative talents and professional qualified teachers.

\subsection{Scientific Student Selection and Expansion Enrollment}

In the face of regional, economic and education level restrictions, the solution of the top-notch innovative class in $\mathrm{G}$ senior high school in western China are adopting scientific student selection and expansion enrollment. In particular, schools should combine their own characteristics and environmental resources to select talents and implement two-way selection. For students who have not been able to enter the top-notch innovative talent classes, they would probably divided into regular classes senior high school; for students entered the top-notch innovative talent classes, if they can not adapt to the teaching methods, they can transfer to the regular class to study, too. Meanwhile, students who get good grades and learned new abilities will also welcomed to join in the top-notch innovative talent classes in the next turn through tests. The rolling system enters the next round of selection. All in all, it is the best education for students when it is a suitable education.

\subsection{Balance the Courses and Strengthen the Liberal Education}

Liberal education is more about "education" than "teaching". Because the choices of liberal education is diversified rather than a clear-cut distinction between science subjects and art subjects. Liberal education is a kind of practical oriented education, students' choices scope are wide, students' personality development are free, and also useful to form students' habit of thinking. [10] So liberal education is the humanities education. Before the arrival of the new college entrance examination reform, $G$ senior high school still need to improve the setting of curriculum, balance school curriculum between art subjects and science subjects, especially in grade two. Reinforce the equality with other teaching methods or activities to compensate the phenomenon of science bias in the process of top-notch innovative talents cultivation which is not correct. In fact, the problem is temporary. With the popularization and deepening of the reform of the college entrance examination, the problem will be solved naturally years later. Parts provinces in China already put new idea of liberal education into college entrance examination now, and G school's future will not be far.

\subsection{University Cooperation and Multiple Outputs}

Judgment from society about the success of top-notch innovative talents cultivation standard by entering a good University or not. And unquestionably this is understandable. But if the problem of single output isn't solved, it is bound to cause social doubt about the meaning of top-notch innovative talent cultivation in regular high schools. So first of all, except the university entrance exam as an ordinary path, the cultivation between Universities and senior high schools has been increasingly become mature in our country, G senior high school can seek resources of colleges and universities in its province. In addition, the school can actively recommend talents to all kinds of colleges and universities, which can attract students from colleges and universities to select talents 
and recruit students independently. What's more, schools and higher education administration could help to implement the policy of applying for guarantee, recommend to overseas study and plus additional score for college entrance examination because of their speciality, rich and multiple top-notch innovative talents graduate output ways will help to promote the career of top-notch innovative cultivating in our country. [11]

\section{Conclusion}

In this key period of transition for China, from a labor pool mainly advantaged by its size to one charactezied by the high quality of its members, it is absolutely necessary to develop a system for cultivating innovative talent among more gifted students. This paper has explored both the experiences and problems of one Chinese public high school's "top-notch innovative talent" cultivation program, suggesting improvements that may benefit both it and the nation's schools at large.

\section{Acknowledgements}

This paper received financing in 2016 from the "Study on The Implementation Path of Education for College Students' Innovation and Entrepreneurship in Shaanxi Provincial Universities" project, through Shaanxi's Science Education department as part of the province's Thirteenth Five-Year Plan.

\section{Appendix}

Questionnaire paper about TNITC for teachers

Dear teachers,

Greeting! I am a master degree student from Baoji University of Arts and Sciences, majoring Educational Management. I am doing this questionnaire survey based on the top-notch innovative talent cultivating class in G senior high school. we are going to cooperate together to do this research and promote our school go further and higher. All information of the questionnaire is only used for statistical research, and it is strictly confidential for other purposes. The questionnaire is filled out without signature, please fill in your true thoughts. Thank you for your cooperation!

November 2017

1. What is your educational background? [single topic] *
( ) College degree
( ) Bachelor degree
( ) Master degree
( ) Doctor degree

2. How long is your teaching experience? [single topic] *
( ) 1-2 years
( ) 3 to 5 years
( ) 5-8 years
( ) 8 years

3. What is your title of job technical post? [single topic] *
( ) Level 2
( ) Level 1
( ) Senior title
( ) Super senior title

4. What kind of core qualities do you think the teachers in the TNITC need? [multiple choice] *
( ) Innovation spirit
( ) Professional knowledge
( ) Advanced thinking
( ) Cooperation awareness

5. In what way did you become TNITC teacher ? [single topic]
( ) School selection
( ) Leadership appointment
( ) Recommended by colleagues
( ) self-recommendation

6. You think that the existing selection method can effectively select students with innovative quality or potential. [single topic] *
( ) Totally agree
( ) Agree
( ) Not sure
( ) Don't agree
( ) Against 
7. In class, you will be able to conduct hierarchical teaching according to the different qualifications of students and pay attention to the cultivation of students' innovative ability. [single topic] *
( ) Totally agree
( ) Agree
( ) Not sure
( ) Don't agree
( ) Against

8. Your knowledge reserve can meet the needs of students and classes. [single topic] *

( )Totally agree

( ) Agree

( ) Not sure

( ) Don't agree

( ) Against

9. School management is scientific and flexible in curriculum setting and class management. [single topic] *
( )Totally agree
( ) Agree
( ) Not sure
( ) Don't agree
( ) Against

10. You think the parents of the students have enough financial ability and are willing to pay the fees in the learning process. [single topic] *
( ) Totally agree
( ) Agree
( ) Not sure
( ) Don't agree
( ) Against

11. Students in your class are no longer limited to traditional teaching and are moving to a more efficient way of learning. [single topic] *

( ) Totally agree

( ) Agree

( ) Not sure

( ) Don't agree

( ) Against

12. Your students are guided by one or more artistic talents with their own interests and hobbies. [single topic] *
( )Totally agree
( ) Agree
( ) Not sure
( ) Don't agree
( ) Against

13. The school has actively carried out the training of top-notch innovative talents and established a special safeguard department and system. [single topic] *
( ) Totally agree
( ) Agree
( ) Not sure
( ) Don't agree
( ) Against

14. What are your expectations for the development of innovative talents in our school? [fill in the blanks] *.

15. What achievements did your class make in the past? [fill in the blanks]

Questionnaire paper about TNITC for students

Dear students,

Greeting! I am a master degree student from Baoji University of Arts and Sciences, majoring Educational Management. I am doing this questionnaire survey based on the top-notch innovative talent cultivating class in $\mathrm{G}$ senior high school. we are going to cooperate together to do this research and promote our school go further and higher. All information of the questionnaire is only used for statistical research, and it is strictly confidential for other purposes. The questionnaire is filled out without signature, please fill in your true thoughts. Thank you for your cooperation! 
November 2017

1. What way did you learn about the TNITC? [multiple choice] *

( ) Acquaintance introduction

( ) Teacher recommended

( ) My friends are reading now.

( ) Media reports

2. Where are you from? [single topic] *

( )City (urban) school.

( ) Rural school

( ) Other cities

( ) Other provinces

3. Do your parents or elders know about TNITC? [single topic] *

( ) very clear
( ) Know some
( ) Very little
( ) Never heard

4. You think you are going to school through scientific and fair selection. [single topic] *

( )Totally agree

( ) Agree

( ) Not sure

( ) Don't agree

( ) Against

5. You think that the professional level of substitute teachers is very high, and they has scientific and innovative thinking, and the classroom is always interesting. [single topic] *
( ) Totally agree
( ) Agree
( ) Not sure
( ) Don't agree
( ) Against

6. The extracurricular activities of each semester will broaden your horizon and help you greatly. [single topic] *

( ) Totally agree

( ) Agree

( ) Not sure

( ) Don't agree

( ) Against

7. Parents pay a lot of money on your study in TNITC. [single topic] *
( ) Totally agree
( ) Agree
( ) Not sure
( ) Don't agree
( ) Against

8. You think that teachers' evaluations of students are not all from academic achievements, but are taken into consideration in other aspects. [single topic] *

( ) Totally agree

( ) Agree

( ) Not sure

( ) Don't agree

( ) Against

9. You think the laboratory and other supporting facilities in the school can meet your learning needs. [single topic] *

( ) Totally agree

( ) Agree

( ) Not sure

( ) Don't agree

( ) Against

10. You think your learning style is more effective and efficient than before. [single topic] *

( ) Totally agree

( ) Agree 
( ) Not sure

( ) Don't agree

( ) Against

11. Except preparing to pass the college entrance examination, you are prepared to study abroad. [single topic] *

( ) Totally agree

( ) Agree

( ) Not sure

( ) Don't agree

( ) Against

12. Your study and life are relatively free and happy compared with friends in other school. [single topic] *

( ) Totally agree

( ) Agree

( ) Not sure

( ) Don't agree

( ) Against

13. For the current class rotation system, you prefer a fixed class management mode. [single topic] *

( ) Totally agree

( ) Agree

( ) Not sure

( ) Don't agree

( ) Against

14. What are the difficulties you often encounter in your study? [fill in the blanks]

15. How do you hope to solve the difficulties you meet? [fill in the blanks]

\section{References}

[1] National medium and long term education reform and development plan (2010-2020). National medium and long term education reform and development planning outline working group office. 2010-07-29.

[2] Bao Shuimei, Li Shiping. The dilemma of China's top-notch innovative talent cultivation and its roots and solutions [J]. Modern education management, 2012(08):83-89.

[3] Yue Siju. On the way to cultivate innovative talents in high school. [J]. Scientific inquiry (education research), 2013(08):38-39.

[4] Gao shuan. Study on the characteristics of high school endowment and its influencing factors [D]. East China normal university, 2013.

[5] Chen jian. Research on training mode of top-notch innovative talent in high school [D]. Ningbo university, 2014.

[6] Song Qiuqian, the theory and practice of education theory and practice in Europe and America [J]. Shandong education scientific research, 2000(04):35-38.

[7] Chen Cui. Solving "Qian Xuesen's question" to seek the way of financing: the "going to university" activity of education research branch of education society in Beijing [J]. Beijing education (general education), 2012(07):18-20.

[8] Lou Yuanyuan. Thinking on cultivating innovative talents in high school and University [J]. Basic education, 2014, 11(03):45-50.

[9] Zhou Guangming, Shuai Kai, Du bin, Zou Xianchun, Zhu Yaping, Chen Shi. Typical model and practice reflection of innovative talent cultivation $[\mathrm{J}]$. Journal of southwest normal university (natural science edition), 2013, 38(05):150-157.

[10] Si Xiaohong, Song Hongxia. Education fairness is the ideal state for the harmonious development of education equality and education efficiency $[\mathrm{J}]$. Education theory and practice, 2008(16):27-30.

[11] Gao Shuan. Study on the characteristics of high school endowment and its influencing factors [D]. East China normal university, 2013.

\section{Biography}

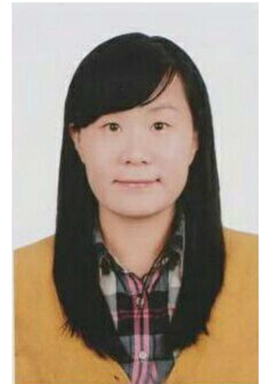

Liu Peng (1986-) female, Han nationality, born in Shaanxi Weinan, Master student majors in Educational management in Baoji University of Arts and Sciences, research area is education innovation. Meanwhile, she has been worked in Weinan Gaoxin middle school as an English teacher for 8 years so far.

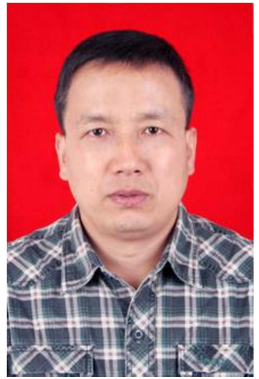

Hu Shaoming (1973-) male, Han nationality, born in Shaanxi Baoji, CPC member, Master's degree, associate professor. Full-time teacher in the teaching and research department of pedagogy, and deputy director of education science and technology department practice teaching management center in Baoji University of Arts and Sciences. 